\title{
Um olhar de viajante para a arte e cultura popular: A tradição dos Caretos na Região de Trás-os-Montes - Portugal
}

\author{
Una mirada de viajero para el arte y la cultura popular: La tradición de \\ los Caretos en la Región de Trás-os-Montes - Portugal
A Traveler's Look at Folk Art and Culture: The Caretos Tradition in the Trás-os-Montes Region-Portugal

\author{
Flávia Demke Rossi ${ }^{1}$
}

\begin{abstract}
Resumo
No ano de 2014, enquanto cursava Artes Visuais - Licenciatura na Universidade Federal de Pelotas (UFPel), tive a oportunidade através de um acordo entre a UFPel e o Instituto Politécnico de Bragança (IPB) em Portugal, de realizar um intercâmbio acadêmico. Logo, pude estudar no Curso de Licenciatura em Arte e Design, no IPB em Bragança, Portugal no período de setembro de 2014 a fevereiro de 2015. Por meio do deslocamento para outro lugar, pude migrar para a região de Trás-os-Montes, a qual se encontra no nordeste de Portugal. Como o próprio nome sugere, é uma região montanhosa e por ter esta característica, em tempos passados o trânsito e o acesso a ela era muito difícil. Assim, desenvolveu-se lá aspectos culturais muito específicos e singulares, bem como uma característica própria e subjetiva do povo transmontano (de Trás-os-Montes) de ser. Com o passar dos dias ia gradativamente conhecendo a música, a dança, a arte, o artesanato, as festividades, as tradições, a culinária e a literatura locais. Bem como, conhecia sua gente, povo simples e acolhedor que na sua generosidade, sem saber contribuía para o meu processo de reterritorialização (Deleuze, 2009). As experiências vivenciadas durante esse percurso, modificaram meu modo de ver e pensar a cultura, o cotidiano, as relações sociais e a própria educação. Deste modo, gostaria de compartilhar neste artigo, um pouco da minha experiência de descoberta do território e da cultura transmontana, principalmente, no que confere aos ritos festivos envolvendo os Caretos, personagens tradicionais de Trás-os Montes.
\end{abstract}

Palavras-Chave: Festa dos Caretos. História, Cultura. Educação.

\section{Resumen}

No ano de 2014, enquanto cursava Artes Visuales - Licenciatura en Universidade Federal de Pelotas (UFPel), una oportunidad através de un acuerdo entre UFPel y el Instituto Politécnico de Braganza (IPB) en Portugal, de realizar um intercâmbio acadêmico. Logotipo, pude estrenar No Curso de Licenciatura en Arte y Diseño, no IPB en Braganza, Portugal, período de septiembre de 2014, fevereiro de 2015. Meio do deslocamento para outro lugar, pude migrar para una região de Trás-os-Montes, un qual se encontra no nordeste de Portugal. Como o próprio nome sugere, é uma região montanhosa e por ter esta característica, em tempos passados o trânsito e ocesces a ela era muito difícil. Assim, desenvolveu-se lá cultura cultural muito específicos e singulares, bem como uma característica própria y subjetiva do povo transmontano (de Trás-os-Montes) de ser. Com o passar dos dias ia gradativamente conhecendo una música, un dança, un arte, o artesanato, como festividades, como tradições, una culinária e una literatura locais. Bem como, conhecia sua gente, povo simples y acolhedor que na sua generosidade, sem sabre contribuía para mi proceso de reterritorialização (Deleuze,

\footnotetext{
${ }^{1}$ Estudante do Mestrado em Educação - PPGE, Especialista em Ensino e Percursos Poéticos; Universidade
} Federal de Pelotas - UFPel; Pelotas, Rio Grande do Sul, Brasil; flavia.demkerossi@gmail.com. 
2009). Como experiencias de vida durante el curso, modificando el modo de ver y pensar en la cultura, o cotidiano, como relaciones sociales y como educación profesional. Deste modo, gosaria de compartilhar neste artigo, um pouco da minha experiência de descoberta do território e da cultura transmontana, principalmente, no que confere aos ritos festivos envolvendo os Caretos, personagens tradicionais de Trás-os Montes.

Palavras-Chave: Festa dos Caretos. História, Cultura. Educação.

\begin{abstract}
In 2014, while attending Visual Arts - Licenciatura at the Universidade Federal de Pelotas (UFPel), I had the opportunity, through an agreement between UFPel and the Instituto Politécnico de Bragança (IPB) in Portugal, to carry out an academic exchange. Therefore, I was able to study at the Degree in Art and Design at the IPB in Bragança, Portugal from September 2014 to February 2015. By moving to another place, I was able to migrate to the region of Trás-os-Montes, which is in the northeast of Portugal. As its name suggests, it is a mountainous region and because having this characteristic, in times past the traffic and access to it was very difficult. Thus, there developed very specific and singular cultural aspects, as well as a proper and subjective characteristic of the Trasmontano people (of Trás-os-Montes) to be. As the days went by, I gradually became acquainted with local music, dance, art, crafts, festivities, traditions, cuisine and literature. As well, I knew his people, simple and welcoming people who in their generosity, without knowing contributed to my process of reterritorialization (Deleuze, 2009). The experiences I had during this course changed my way of seeing and thinking about culture, daily life, social relations and education itself. In this way, I would like to share in my article a little of my experience of discovering the territory and culture of the Transmontana, especially in what confers the festive rites involving the Caretos, traditional characters of Trás-os Montes.
\end{abstract}

Keywords: Caretos Festival. History, Culture. Education.

\title{
1. Introdução
}

No ano de 2014, enquanto cursava Artes Visuais - Licenciatura na Universidade Federal de Pelotas (UFPel), tive a oportunidade através de um acordo entre a UFPel e o Instituto Politécnico de Bragança (IPB) em Portugal, de realizar um intercâmbio acadêmico. Logo, pude estudar no Curso de Licenciatura em Arte e Design, no IPB em Bragança, Portugal no período de setembro de 2014 a fevereiro de 2015.

Por meio do deslocamento para outro lugar, para um país além do Oceano Atlântico, pude migrar temporariamente para um espaço localizado no "cimo de Portugal, como os ninhos ficam no cimo das árvores", nas palavras de um importante escritor português da região onde estive: Miguel Torga. Trata-se da região de Trás-os-Montes, a qual se encontra no nordeste de Portugal. Como o próprio nome sugere, é uma região montanhosa e por ter esta característica, em tempos passados o trânsito e o acesso a ela era muito difícil. Devido a este isolamento geográfico, desenvolveu-se lá aspectos culturais muito específicos e singulares, bem como uma característica própria e subjetiva do povo transmontano (de Trás-os-Montes) de ser. Estes aspectos pude conhecer vivendo na cidade de Bragança, visitando cidades vizinhas e aldeias da zona rural. 
Em Trás-os-Montes, no seu vasto território de zona rural, é perceptível a integração do ser humano com a natureza que se evidencia na arquitetura das casas de pedra, na agricultura e criação de animais para a subsistência, nos ritos festivos e demais aspectos culturais de seu povo. Esta característica foi reconhecida através da candidatura da "Reserva da Biosfera Transfronteiriça Meseta Ibérica", que abrange os municípios da região transmontana somados aos municípios espanhóis de fronteira. Tudo para que aquele espaço seja reconhecido pela UNESCO, como um território que traz por excelência uma simbiose entre o ser humano e a biosfera. Nesse contexto de integração de homens e mulheres com o meio onde vivem, poderia se dizer que "não o rosto, mas a face é paisagem, pois nela se imprimem as marcas do tempo e da experiência vivida pelo sujeito. Nem só as pessoas têm face, também as tem os lugares, marcados pelas ações de sua própria natureza, tanto quanto por ações humanas." (Meira, 2009, p.94)

Com o passar dos dias no "Reino Maravilhoso de Trás-os-Montes", como descrevia Miguel Torga, ia gradativamente conhecendo a música, a dança, a arte, o artesanato, as festividades, as tradições, a culinária e a literatura locais. Bem como, conhecia sua gente, povo simples e acolhedor que na sua generosidade, sem saber contribuía para o meu processo de reterritorialização. As experiências vivenciadas durante esse percurso, modificaram meu modo de ver e pensar a cultura, o cotidiano, as relações sociais e a própria educação. Deste modo, gostaria de compartilhar neste artigo, um pouco da minha experiência de descoberta do território e da cultura transmontana, principalmente, no que confere aos ritos festivos envolvendo os Caretos, personagens tradicionais de Trás-os Montes.

\section{Desenvolvimento}

Com a intenção de conhecer a região e a cultura transmontana, segui de ônibus, na manhã de 31 de outubro de 2014 em direção a Vinhais, município vizinho a Bragança, onde haveria o I Seminário Internacional de Máscaras Artesanais. O caminho tortuoso era compensado pelas belas paisagens outonais no relevo montanhoso. Quando cheguei em Vinhais, segui minha vontade de deambular e descobrir os encantos daquela pequena cidadezinha, que ainda conservava traços medievais repletos de história.

Ao adentrar no espaço onde se realizava o I Seminário Internacional de Máscaras artesanais, fiquei impressionada com a quantidade de máscaras, das mais variadas formas, feitios, cores e materiais, que de súbito despertaram em mim a admiração por aquele fazer artístico/artesanal. Os artesãos e artesãs colocavam-se junto de suas criações. Ora 
conversavam com os visitantes, ora concentravam-se no trabalho de entalhar a madeira ou moldar o latão por exemplo, na confecção de novas máscaras.

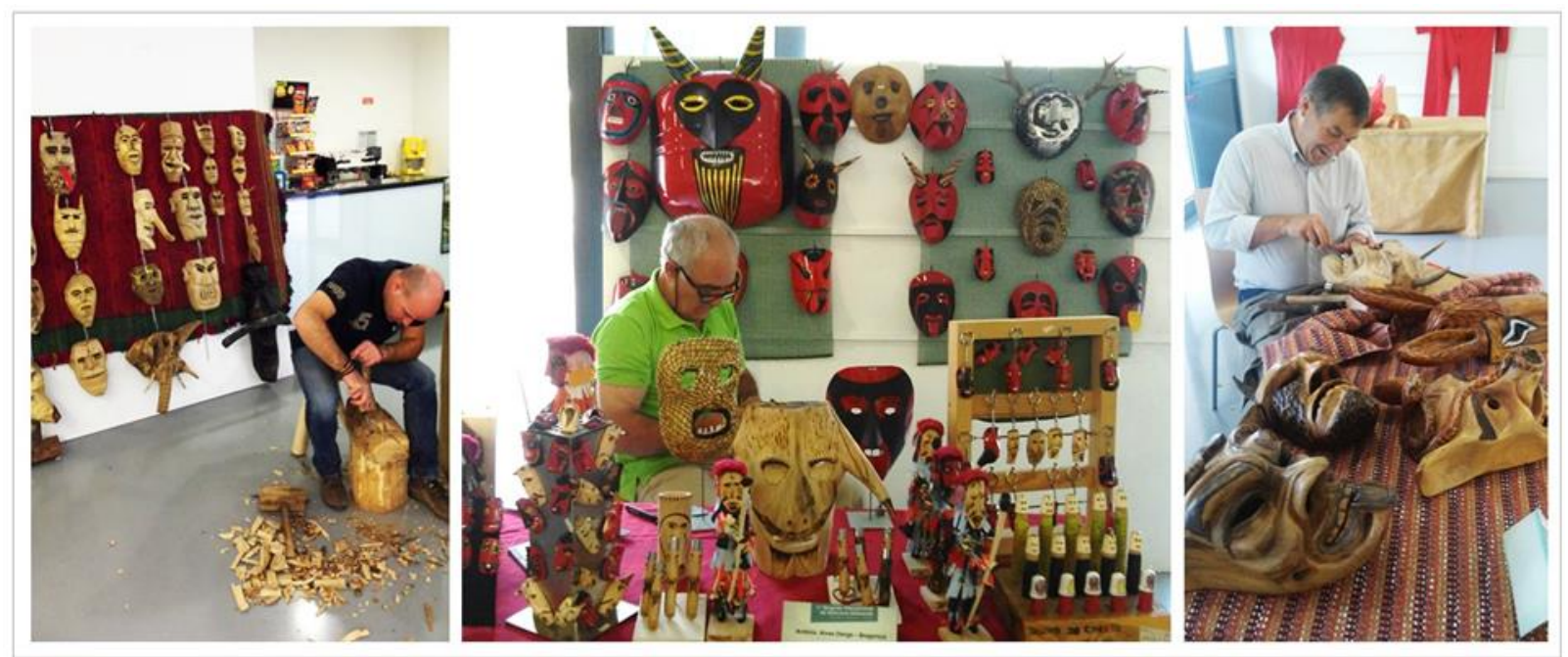

Figura 1: Artesãos no I Simpósio Internacional de Máscaras Artesanais. Fonte: Acervo pessoal, 2014

Tradicionalmente, as máscaras que se apresentavam naquele ambiente eram e são utilizadas pelos Caretos durante as festividades em datas especiais. Os Caretos são personagens singulares da cultura Transmontana (em Portugal) e da vizinha: Província de Zamora na Espanha. Estão presentes nas "Festas dos Rapazes" que ocorrem no período natalino ou posteriormente no dia de Reis e podem ter distintas denominações nas aldeias transmontanas. Eles também são protagonistas das festividades relacionadas ao carnaval, o chamado Entrudo. Em cada aldeia a tradição ganha contornos particulares, relacionados as vestimentas, as máscaras e as ações/rituais praticados durante a festa.

Durante o seminário sobre as máscaras artesanais, conversei com outros três artesãos locais que me revelaram muitos aspectos dessa tradição e da confecção das máscaras. Seu António, natural da Aldeia de Varge - Bragança, era um dos artesãos presentes. Em suas palavras, tudo começou aos quinze anos de idade,

Quando fui convidado pelos mordomos [rapazes mais velhos] para entrar nas festas [dos Rapazes], e decidi fazer a máscara que eu iria usar durante aqueles dois dias. Encontrei uma lata velha comecei a molda-la e daí saiu a minha primeira máscara. (António Alves. Artesão de Bragança. Depoimento, 31/10/2014).

Artesão/artista autodidata, com grande carinho pelo seu trabalho, fez a mim a seguinte revelação sobre o processo de criação e confecção das máscaras, 
Inspiro-me na cara das pessoas quando estão zangadas, admiradas, infelizes, etc. $\mathrm{O}$ processo de criação, se for de chapa, é fazer um molde, cortar a chapa e moldá-la. Em seguida rebordá-la, abrir os olhos, boca e nariz; depois colocar o nariz e lixá-la. Por fim dar-lhe a base de pintura e depois secá-la e maquiá-la. Ao fazê-la sinto-me um criador. (António Alves. Artesão de Bragança. Depoimento, 31/10/2014).

Para Ostrower (2012), a criatividade está intrinsecamente relacionada com a sensibilidade do criador e da cultura na qual ele se insere, sendo a mesma, um ato consciente de expressão. “[...] entendemos que precisamente na integração do consciente, do sensível, e do cultural se baseiam os comportamentos criativos do homem. Somente ante o ato intencional, isto é, ante a ação de um ser consciente, faz sentido falar de criação" (Ostrower, 2012, p.11). Afirmação que vai ao encontro com este contexto de criação vivenciado pelos artesãos de máscaras tradicionais de Trás-os-Montes.

Sobre as técnicas e materiais empregados, Seu António contou que se utiliza de diversos materiais como: folha de flandres, chapa de zinco, alumínio, latão, madeira, cabaça (porongo) e escrinho (palha e silvas). Sobre este último material, ele disse-me que a técnica para a confecção das máscaras em palha era original de uma aldeia que hoje é despovoada, configurando-se um saber extinto recuperado por ele.

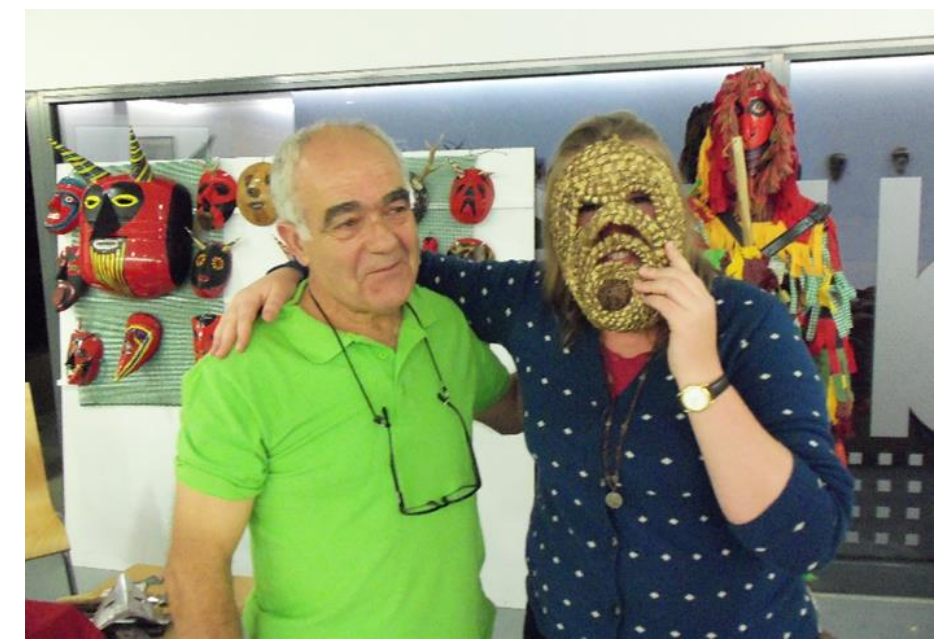

Figura 2: Seu António e eu com a sua máscara de palha. Fonte: Acervo pessoal, 2014.

A máscara encobre a identidade do sujeito que a utiliza, dando-lhe liberdade durante a festa e o ajuda a personificar de modo fictício a figura a ele atribuída. Para Seu António "Foi uma experiência inesquecível, pela folia, pela autonomia, pela liberdade de falar e gesticular de cara coberta e trajado diabolicamente etc." (António Alves. Artesão de Bragança. Depoimento, 31/10/2014).

Sobre o processo de construção das máscaras, Tiza (2013) aponta que: 
Em todo o caso, o processo de construção não diferia muito de uns para os outros. A máscara saía sempre das mãos rudes, calejadas quiçá, dos artistas deste povo, ultrapassando a dimensão utilitária e decorativa para se transformar em objeto ritual. $\mathrm{Na}$ verdade, a máscara sempre foi concebida para o exercício de atos solenes da festa, como se de utensílios sagrados se tratasse. Ainda assim e independentemente da faceta sacral, a máscara, quando saída das mãos do povo sempre adquire uma dimensão transcendente, a dimensão de toda uma cultura de saber e saber-fazer ancestral materializada em formas de equilíbrio e beleza únicos. (TIZA, 2013, Os Construtores de Máscaras. Ano: 2013. Disponível em: http://www.academiaibericamascara.org. Acessado em 20 de setembro de 2015)

Com as palavras de Tiza (2013) posso refletir sobre o caráter ritualístico das máscaras transmontanas. Já diria Lévi-Strauss, “Uma máscara não é aquilo que representa, mas aquilo que transforma, isto é: o que escolhe não representar”. Ao experimentar algumas máscaras expostas no seminário, senti um pouco de medo antes de colocar e um sentimento de estranheza e euforia quando as provei. Imagino que as emoções sejam multiplicadas com a experiência de ser Careto em alguns dias do ano e participar das tradições em grupo.

Mas afinal o que fazem os Caretos? Como são estes festejos? Segundo os relatos dos artesãos que entrevistei, os Caretos são rapazes que dos quinze anos até a idade que se casam, protagonizam a "Festa dos Rapazes" (ou "Festa de Santo Estêvão" para algumas aldeias), realizando todo o tipo de travessuras enquanto dançam ao som da música típica transmontana. O comportamento destes mascarados consiste de saltos, gargalhadas, atirar feno nos moradores, roubar o fumeiro nas casas (embutidos produzidos de forma artesanal) e "achocalhar" as moças. Ou seja, encostar nas moças os chocalhos que carregam presos à cintura, em uma espécie de dança que na tradição tem a intenção simbólica de torná-las férteis.

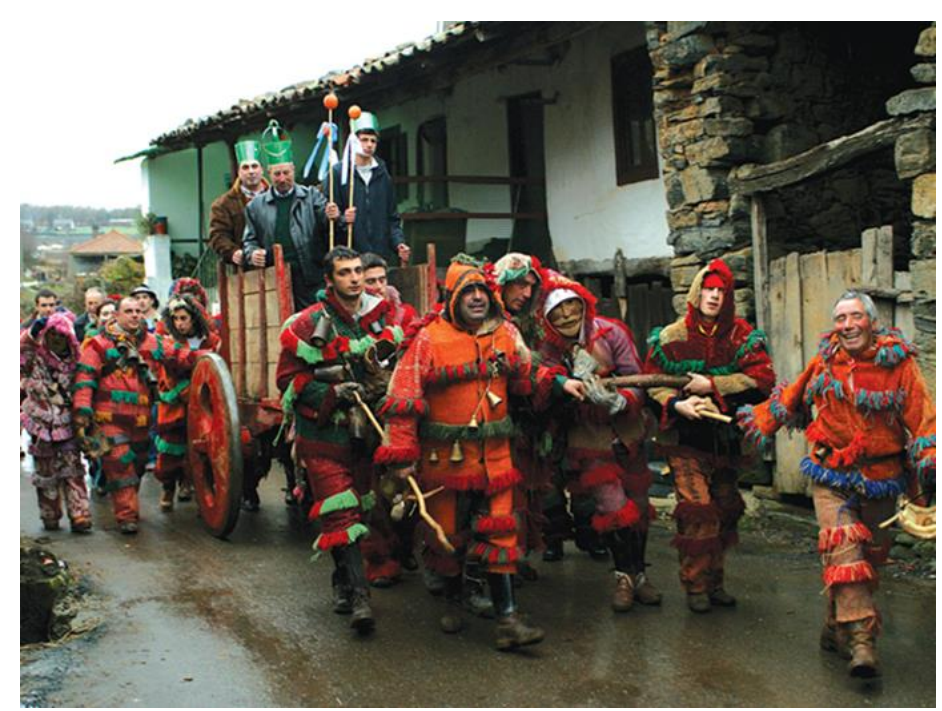


Figura 3: Festa de Santo Estêvão na Aldeia de Ousilhão - Vinhais. Fonte: http://museudamascara.cm-braganca.pt/. Acessado em 31/10/2015

A origem destas figuras tradicionais da cultura transmontana ainda é incerta. $\mathrm{Na}$ sabedoria popular, a tradição pode ser uma reminiscência de antigos rituais pagãos associados às raízes celtas do território, num período anterior a ocupação romana, ou seja, há mais de dois mil atrás. Para os antropólogos, a tradição dos Caretos é como um rito de passagem dos jovens para a vida adulta. A personagem do Careto teria também a função social de mostrar lado obscuro do ser humano através das brincadeiras e malcriações; que não são mal vistas por que fazem parte da cultura. Ou seja, aceita-se e acolhe-se a errância dentro da própria comunidade. Acredita-se que os atos errantes dos Caretos seriam uma maneira de expurgar o mal e purificar a comunidade para o novo ano. (Carneiro, 2014).

Associo a tradição dos Caretos ao conceito de errância proposto por Maffesoli (200), que a vê como base fundadora para a própria sociedade:

A errância é coisa do tipo que além de seu aspecto fundador de todo conjunto social, traduz bem a pluralidade da pessoa, e a duplicidade da existência. Também exprime a revolta, violenta ou discreta, contra a ordem estabelecida [...] (MAFFESOLI, 2001, P.16).

Para este autor, os anos de errância juvenil constituem uma tradição em todas as culturas e todas as sociedades. Tradicionalmente só os rapazes solteiros acima de quinze anos poderiam ser Caretos, mas atualmente com o despovoamento das aldeias, tem-se admitido cada vez mais a participação feminina. A elas era somente destinada a tarefa da confecção dos fatos - as vestimentas dos Caretos. As formas variavam (e variam) de aldeia para aldeia, mas na maioria das vezes são usados retalhos de lã ou outros tecidos, costurados de modo a destacar o colorido e o movimento das roupas. Segue os exemplos:
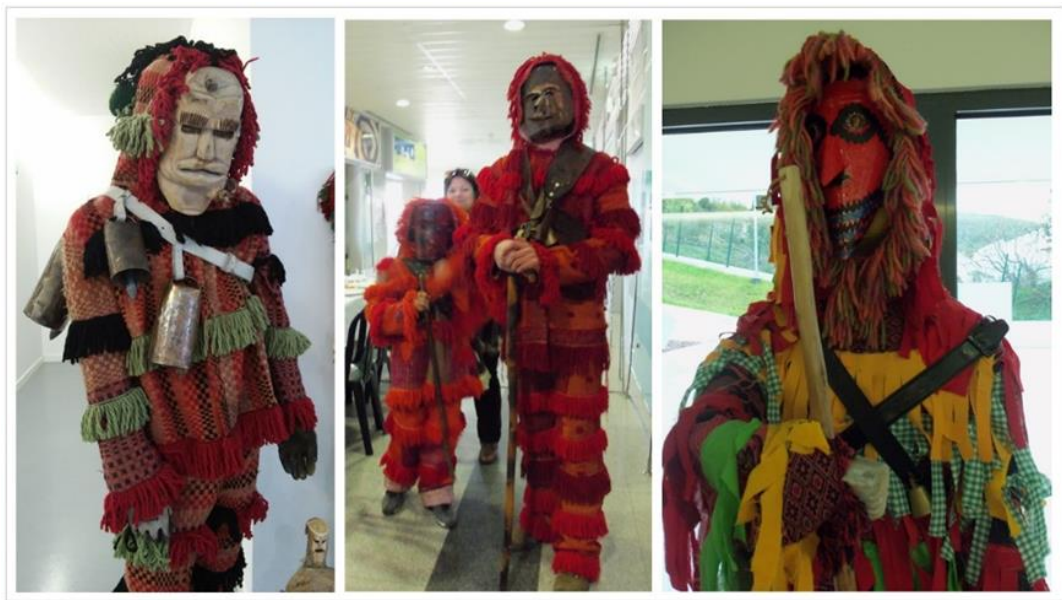
Figura 4: "Fatos" dos carretos das aldeias de Ousilhão - Vinhais, Salsas - Bragança, e Varge - Bragança, respectivamente. Fonte: Acervo pessoal, 2014.

Ainda sobre a conversa com os artesãos durante o evento em Vinhais, evidencio o aspecto artístico e laboral que envolve a produção das máscaras. Seu Amável, artesão/artista natural de uma aldeia do município de Miranda do Douro, contou-me esta história:

... Vi um pedaço de pau no rio com formas muito bonitas que me despertou interesse. Levei para casa e fiz duas máscaras no mesmo pau, mostrei aos amigos que ficaram incrédulos, duvidando mesmo se tinha eu feito aquele trabalho. A partir daí, nunca mais parei [de produzir as máscaras]. (Amável Antão. Artesão de Bragança. Depoimento, 31/10/2014)

A partir de então, sua técnica tem se aprimorado e suas máscaras adquirindo cada vez mais singularidade e expressividade. "Sem fugir do tradicional gosto de mostrar a minha criatividade, sinto-me orgulhoso daquilo que faço", salienta Seu Amável. Confeccionadas com ferramentas de seu avô, suas máscaras são procuradas por colecionadores em sua maioria. Por trabalhar em um museu de arte e história em Bragança, Seu Amável vê a possibilidade de ensinar aos jovens o seu artesanato, na intenção de preservar e perpetuar as tradições transmontanas.
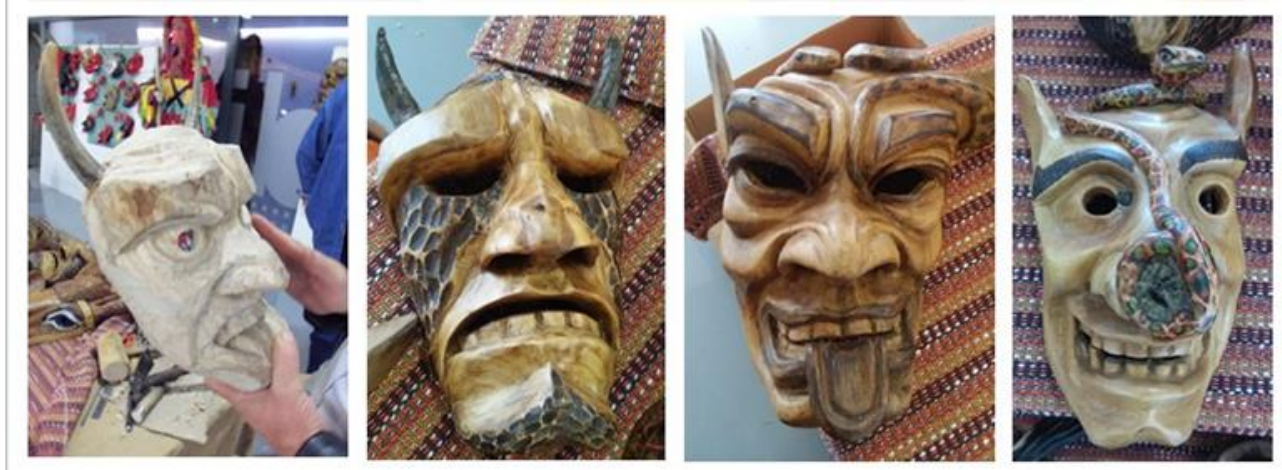

Figura 5: As máscaras de Seu Amável. Fonte: Acervo pessoal, 2014.

Outro artesão preocupado com a perpetuação da tradição através das gerações, chamase Victor. Ele assim como o Seu António, já foram Caretos, e isto o motivou para iniciar a produção das máscaras. Nas palavras de Victor:

Comecei a fazer máscaras por curiosidade, na festa de Santo Estevão, 24/25/26 de dezembro. $\mathrm{Na}$ aldeia os rapazes vestem fatos e mascaram-se e eu quis fazer a minha própria máscara, a partir daí comecei a fazer e nunca mais parei. (Victor Afonso. Artesão de Vinhais. Depoimento, 31/10/2014) 
Os objetos produzidos pelo artesão/artista possuem uma estética mais rústica, com aparência próxima as máscaras usadas nas festas de Santo Estevão, como é chamada a "Festa dos Rapazes" na sua aldeia, a Aldeia de Ousilhão - Vinhais. Esta celebração é para Afonso e Patrocínio (2009), um misto de cerimônias religiosas com ritos profanos, que representam ritos de passagem relacionados a fertilidade e a fecundidade, em uma época de transição dos anos e de renovação da natureza.

Em relação as máscaras, o artesão/artista Victor, aponta que elas são feitas geralmente em madeira de castanho, comum na região. A criação destas, ocorre durante o processo de confecção. "A máscara surge naturalmente. Dependendo do pau, os defeitos que ele tem, aproveitam-se para fazer certos detalhes da máscara. Cada uma é única. " (Victor Afonso. Artesão de Vinhais. Depoimento, 31/10/2014).

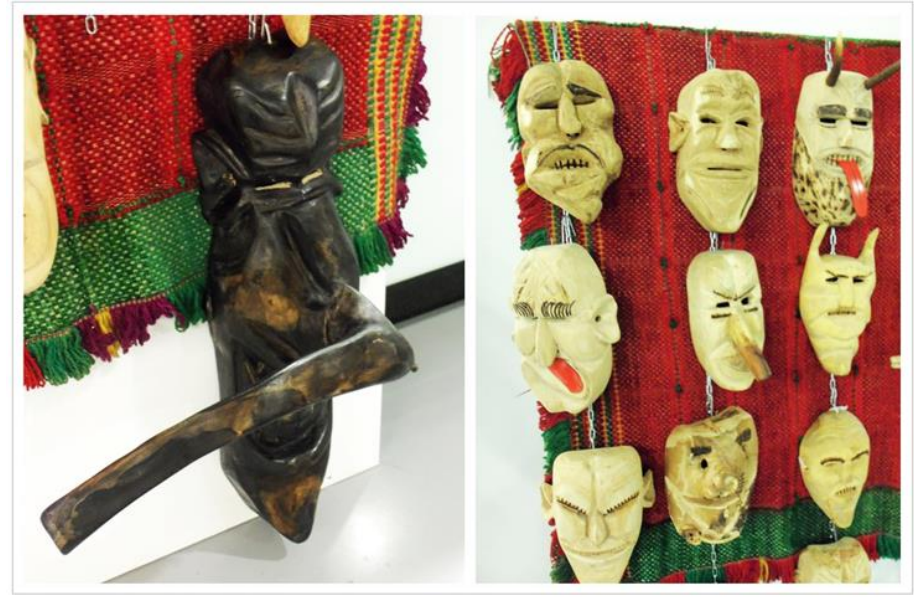

Figura 6: Máscaras do artesão/artista Victor Afonso. Fonte: Acervo pessoal, 2014

Tão logo conversei com os artesãos que conheci no seminário, comecei a pensar na dimensão artística, histórica e cultural que aquele fazer e seus objetos carregam. Ao perceber a singularidade dos trabalhos expostos e a marca que cada artesão imprime sobre a sua criação, comecei a refletir sobre a tênue linha que separa a arte do artesanato e a questionar essa existência.

Não existe uma arte definitiva. Tradicionalmente, a arte tem sido reflexo da cultura que se desenvolveu.... Para que a arte seja válida, deve refletir o indivíduo que a produz.... Nenhuma obra de arte se mantém isolada da cultura em que se manifestou, nem do indivíduo que a engendrou. $O$ trabalho artístico não pode ser criado por alguém que não esteja profundamente envolvido, pois a arte se manifesta à base das emoções do homem e expressa as experiências e necessidades do autor da obra (LOWENFELD; BRITTAIN, 1977 apud IAVELBERG, 2017, p. 78) 
Para os artesãos, a potência criativa de se trabalhar com máscaras é um fator motivador nas produções, pois o trabalho se constituí como um desafio para a imaginação e a técnica. A própria interação dos artesãos com a sua arte em construção é um meio para a sua própria formação enquanto sujeito, integrado e inserido em sua cultura e espaço de vivência. A criação das máscaras por estar ligada a cultura rural das aldeias, tem um caráter afetivo e familiar a estes artesãos.

O humano não se constitui no sujeito, nem no objeto, mas no conhecimento sensível que se gera na interação de ambos, quando então se instaura um mundo de sentido para ambos. [...] A instauração qualitativa de interações criativas com o ambiente, a cultura, a linguagem, é responsável pelo desenvolvimento do sentido do humano em nós. (MEIRA, 2009, p. 124)

Os encontros que se sucediam com as pessoas e com a cultura, era para mim uma forma de perceber a vida enquanto Arte, enquanto relação que se estabelece com o outro e com o meio. A cada nova descoberta, referentes as histórias contadas, as músicas ouvidas, as comidas provadas, as tradições vivenciadas, a arte e o artesanato fruído.... Foram experiências que por serem sentidas pelos sentidos, foram se tornando saberes incorporados em um processo de constante aprendizado, formação e transformação.

\section{Conclusão}

$\mathrm{O}$ ato de se colocar a caminho, deslocar-se, conhecer outra cultura e permitir-se a experiência deste contato, de certa forma, poderia ser comparado com a docência. Para Ranciére (2010) “aprendemos e ensinamos, agimos e conhecemos também enquanto espectadores que ligam constantemente o que vêem com aquilo que já viram ou disseram, fizeram e sonharam." (Ranciere, 2010, p. 28). Deste modo, entendo que o deslocamento foi um fator essencial para minha formação no que confere a minha compreensão sobre as relações intrínsecas entre arte, cultura e cotidiano.

Uma das maiores contribuições para isso, é o conhecimento que obtive através da experiência direta com os artesãos/artistas das máscaras transmontanas. A percepção de que aquele objeto não é apenas uma máscara, mas um componente essencial para as festividades de caráter ritualístico com origem milenar, traz consigo um aprofundamento sobre a importância da cultura na formação do próprio povo e sua identidade. No entendimento de que a cultura "são as formas materiais e espirituais com que os indivíduos de um grupo 
convivem, nas quais atuam e se comunicam e cuja experiência coletiva pode ser transmitida através de vias simbólicas para a geração seguinte" (Ostrower, 2012, p.13).

Concordo com Duarte Jr (2000), que acredita que o saber comum, histórico tradicional, precisa ser considerado uma missão da educação nos dias atuais, não somente com vistas a preservação, bem como uma valorização do ambiente e dos antigos saberes através do estímulo a sensibilidade. Com este pensamento, gostaria de agregar estas minhas experiências extra acadêmicas a minha formação docente em Arte, por entendê-las como parte do meu processo de formação/transformação.

A experiência de viver em diferentes culturas significou repensar diferentes conceitos, entre eles o de Artes Visuais, das fronteiras entre arte e artesanato, das relações reflexivas sobre o espaço e tempo na Arte. Tais questões mostraram que é necessário expôr relações mais fluidas entre formas e fazeres artísticos, menos hierárquicos em espaços que devem trabalhar mais igualdades, mais conhecimento sensível.

\section{Referências}

AFONSO, Roberto de Morais; PATROCÍNIO, Teresa A. R.; Guia do Ecomuseu de Vinhais. Câmara Municipal de Vinhais: Corane, 2009.

CARNEIRO, Carlos; Caretos. Ano: 2014. Disponível em: http://www.portugalnummapa.com/caretos/. Acessado em 20 de setembro de 2015.

DUARTE Jr, João Francisco; $O$ sentido dos sentidos: a educação (do) sensível. Tese de Doutorado. Faculdade de Educação - UNICAMP, 2000.

HALL, Stuart. Da Diáspora: Identidades e Mediações Culturais. Belo Horizonte: Editora UFMG: 2006.

IAVELBERG, Rosa. Arteleducação modernista e pós-modernista: fluxos na sala de aula. Porto Alegre: penso, 2017.

LARROSA, Jorge. Notas sobre a experiência a e o saber da experiência. Revista Brasileira de Educação: 2002.

MAFFESOLI, Michel. Sobre o Nomadismo: Vagabundagens pós-modernas. Rio de janeiro: Record, 2001.

Matos, Fonseca \& Associados e RCL imagem e comunicação. Guia Terra Fria Transmontana. Versão e-Book a partir da $2^{\mathrm{a}}$ edição, revista e ampliada, 2014. Disponível em: http://www.rotaterrafria.com/. Acessado em 20 de setembro de 2015.

OSTROWER, Fayga. Criatividade e processos de criação. Petrópolis: Vozes, 2012. 
SIZA, M. Teresa; O espelho fraterno. In: Georges Dussaud. Centro de Fotografia Georges Dussaud. Catálogo. Câmara Municipal de Bragança: Abril de 2013.

TIZA, António A. Pinelo; Os Construtores de Máscaras. Ano: 2013. Disponível em: http://www.academiaibericamascara.org. Acessado em 20 de setembro de 2015.

; GUTIÉRREZ, Jesús Núñes; Catálogo Máscara Ibérica. Catálogo.

Câmara Municipal de Bragança, 2013.

TORGA, Miguel; Um Reino Maravilhoso (Trás-os-Montes). In: MOURÃO FERREIRA, David (Org.) Portugal - A terra e o homem: Antologia de textos de escritores do século XX. II Volume. Edição da Fundação Calouste Gulbenkian, 1979.

\section{Meios Eletrônicos Consultados:}

Câmara Municipal de Bragança. Disponível em: http://www.cm-braganca.pt/. Acessado em 01/10/2015.

Câmara Municipal de Vinhais. Disponível em: http://cm-vinhais.pai.pt/. Acessado em 01/10/2015.

Caretos de Varge: Artesão António Alves. Disponível em: http://caretosvarge.blogspot.com.br/. Acessado em 01/11/2015.

Terra Fria Transmontana. Disponível em: http://www.rotaterrafria.com/pages/1. Acessado em $01 / 10 / 2015$. 